\title{
Cultural spaces of climate
}

\author{
Georgina Endfield • Carol Morris
}

Received: 3 October 2011 / Accepted: 25 January 2012 / Published online: 16 February 2012

(C) Springer Science+Business Media B.V. 2012

Climate change has become a dominant environmental narrative at the start of the twenty first century. The political and media focus on the possible implications of climate change, however, the predominantly scientific discourse in which this is couched, and the increasingly globalscale of climate thinking, have obscured the culturally specific and spatially and temporally distinctive meanings of climate more generally (Ross 1991; Hulme 2008a, b). Climate and its cultural significance have, in effect, become decoupled, and popular conceptualisations and discourses of climate, and its manifestations through local weather, have been replaced by a global, and predominantly scientific, meta-narrative. Moreover, contemporary debates over the 'imminent' climate threat obscure a long, complicated history of public engagement in meteorological science and changing ideas about climate.

There have been different ideological and symbolic constructions of climate at different points in history and in order to better understand these distinctive meanings, it has been argued that there is a need to reintroduce particularity to the debate (Hulme 2009). Recent geographical scholarship, for example, has called for research that considers the 'idea' of climate as a "hybrid phenomenon" which can and should be constructed, not only through the use of meteorological statistics but also "inside the imagination", through "sensory experiences, mental assimilation, social learning and cultural interpretations" (Hulme et al. 2009: 197), while there is a need to understanding of how different groups of people in different spatial contexts conceptualise and understand climate and its fluctuations (Hassan 2000; Adger 2003). Such work would investigate climate (and weather) as a function of personal memory, experience and intergenerational transfer of 'climate knowledge' (Hulme 2009: 330), and by definition, demands a more intimate spatial resolution than global perspectives can offer.

Various publications have begun to focus on cultural histories of attitudes toward the weather (Jankovic 2001: Golinski 2007; Boia 2005; Anderson 2005), the myriad ways in which humans have understood the idea of climate across a range of temporal and spatial scales (Fleming et al. 2006), and the genealogy of climate change debates (Fleming 1998). Such approaches are demonstrating the importance of spatially, temporally and culturally

G. Endfield $(\bowtie) \cdot$ C. Morris

School of Geography, University of Nottingham, University Park, Nottingham NG7 2RD England, UK

e-mail: georgina.endfield@nottingham.ac.uk 
specific understandings of climate and, it follows, a changing climate. But there are still only a handful of researchers "engaged in the social and cultural processes of speaking about climate change, of the formation and using of lay knowledge of the formation .... and popular explanations of climate and its interaction with people" (Von Storch and Stehr 2006: 112) and there is still much to be done at the "fluid boundaries between climate, space and culture" (Bailey 2008: 420).

This special issue, therefore, draws on international expertise in order to identify ways to re-particularise climate change discourses, to explore the meaning of climate and weather for different groups at different points in time and to question the ontological status of climate. The papers included were presented at a set of sessions on "Cultural Spaces of Climate" held at the Royal Geographical Society (with the Institute of British Geographers) Annual Conference, Manchester, UK in 2009.

In his paper in this special issue Mike Hulme (2012) explores one way in which "the different worlds inhabited by the idea of climate may be revealed". He focuses on the way in which a heatwave which occurred in July 1900 in the county of Norfolk, England, can be shown to inhabit a suite of "different worlds", namely: the imaginative world of L P Hartley in his novel The Go Between; the historical world of late Victorian Norfolk; and the digital world of the climate sciences.

The "relational context" of climate, that is to say "the places people live, their histories, daily lives, cultures or values" is being identified as critical for understanding how different groups of people in different places comprehend and respond to climate change (Slocum 2004). Place and space have significant and to some extent pivotal roles to play in the production, reception, circulation, application and testing of climate change knowledge. Provincial cultures, for example, are thought to have been critical to the shaping of meteorological endeavour in the past (Naylor 2006; Finnegan 2005). The science of climate change, past and present, also bears the marks of its place of production. For this reason, Jankovic and Hebbert's (2012) study of city climates is a particularly welcome addition to this collection. In their paper they describe the sequence of discovery of the urban heat island since the early nineteenth century, and the emergence and consolidation of a scientific field devoted to the climatology of cities. Yet they also consider the attempts to apply knowledge of climatic factors to the design and management of settlement.

Place may figure no less prominently in the way in which contemporary climate change debates are framed and indeed experienced today, while recent surveys are also suggesting that discourses about climate change need necessarily to be situated within people's locality, as a means of increasing its saliency. Local circumstances, the "everyday experiences and locality", or the situated nature of climate are increasingly being recognised as fundamental to understanding how the public perceives, responds and adapts to climate change (Lorenzoni and Pigeon 2006: 80; see also Palutikof et al. 2004).

In Jones et al.'s (2012) paper, they consider the temporal and spatial specificities and complexities of understanding vulnerability, adaptation and resilience through a detailed case study of the consequences of the severe winter of 1946/1947 in Cwm Tywi, an upland sheep farming community in Wales. Using a mixture of interviews, oral histories, and documentary accounts, the authors demonstrate the perceptions of the extreme nature of this event and the community's ability to mitigate as a result of rurality, self-sufficiency and remoteness. They argue that, despite showing great resilience during the snowiest winter on record, in comparison with other, more urban communities, the inhabitants eventually abandoned their homes because of the emotional distress caused by the loss of a large proportion of their livestock.

Geoghegan and Brace Leyshon's (2012) paper, which considers how climate change can be understood through the workings of farming as an environmental practice addresses both 
the intellectual approaches to the study of climate change and the problems of definition through a case-study of lay narratives of climate change grounded in farming practice on the Lizard Peninsula, Cornwall. Their paper reveals how climate change "as a particular environmental discourse is constructed through memory, observation and conversation as well as materialised in farming practices" in this area.

A focus on scientific explanations of climate change has also served to overlook the contributions of other interest groups. Enthusiasts and amateur societies, for example, played a pivotal role in the production of climate knowledge in the 18th and early 19th centuries and the spaces in which this amateur knowledge was produced and circulated has been highlighted as significant in this process (Jankovic 2001; Naylor 2006). The professionalisation of meteorological science in the late 19th century did not wholly supersede this amateur tradition. Yet there has been a relative neglect of the role of the amateur in contemporary discourses about climate and weather. Recognition of the complexity and uncertainty associated with the physical and cultural dimensions of climate change, however, has heralded a new period of amateur engagement that involves the participation of diverse groups in the production of climate knowledge. The perspectives of amateur groups have the potential to address some of the gaps in climate change knowledge, could help formulate, frame and inform key debates therein. Endfield and Morris' (2012) paper considers the actual and potential contribution of contemporary amateur meteorologists in this respect, drawing on semi-structured interviews with members of one UK based amateur meteorological organisation - the Climatological Observers Link (COL).

Finally David Livingstone's concluding afterword (2012) reflects on the new spaces into which climate research is extending, which as the preceding papers demonstrate, include the literary imagination, urban architecture, the individual, amateur worlds and the marginal, or vulnerable environments. He also demonstrates, in his words "the fertility of this essentially chorographic impulse applied to climatic inquiries", and highlights the growing importance of considering the spatial and temporal specificities in the actual experience of climate. There are, he concludes, three principles that emerge through the papers presented in this special issue namely the need to problematise knowledge claims, particularize climatic experience, and pluralize the meanings of climate and also climatological expertise. It is these principles which e feel will frame the challenges for future cultural climate research.

\section{References}

Adger WN (2003) Social capital, collective action and adaptation. Econ Geogr 79(4):387-404, on 387

Anderson K (2005) Predicting the weather: Victorians and the science of meteorology. University of Chicago Press

Bailey I (2008) Geographical work at the boundaries of climate policy: a commentary and complement to Mike Hulme. Trans Inst Br Geogr 33(5):420-423

Boia L (2005) The weather in the imagination. University of Chicago Press

Endfield GH, Morris C (2012) Exploring the role of the amateur in the production and circulation of meteorological knowledge. Climatic Change (special issue on the Cultural Spaces of Climate)

Fleming JR (1998) Historical perspectives on climate change. Oxford University Press

Fleming JR, Jankovic V, Coen D (2006) Intimate universality. Local and global themes in the history of weather and climate. Watson International Publishing

Finnegan DA (2005) Natural history societies in late-Victorian Scotland and the pursuit of local civic science', British Journal for the History of Science 38(1):53-72

Geoghegan H, Brace Leyshon C (2012) On climate change and cultural geography: farming on the Lizard Peninsula, Cornwall, UK Climatic Change (special issue on the Cultural Spaces of Climate)

Golinski J (2007) British weather and the climate of enlightenment. Chicago University Press 
Hassan F (2000) Environmental perception and human responses in history and prehistory. In: McIntosh RJ, Tainter JA, McIntosh SK (eds) The way the wind blows: climate, history and human action Columbia University Press pp. 121-140

Hulme M (2008a) The conquering of climate: discourses of fear and their dissolution. Geogr J 174(1):5-16, 13

Hulme M (2008b) Geographical work at the boundaries of climate change. Trans Inst Br Geogr 33:5-11

Hulme M (2009) Why we disagree about climate change. Cambridge University Press

Hulme M (2012) 'Telling a different tale': literary, historical and meteorological readings of a Norfolk heatwave. Climatic Change (special issue on the Cultural Spaces of Climate)

Hulme M, Dessai S, Lorenzoni I, Pigeon N (2009) Unstable climates: exploring the statistical and social constructions of 'normal' climate. Geoforum 40(2):197-206

Jankovic V (2001) Reading the skies. A cultural history of the english weather, 1650-1820. Manchester University Press

Jankovic V, Hebbert H (2012) Hidden climate change - urban meteorology and the scales of real weather. Climatic Change (special issue on the Cultural Spaces of Climate)

Jones CA, Davies SJ, Macdonald N (2012) Examining the social consequences of extreme weather: the outcomes of the 1946/1947 winter in upland Wales, UK. Climatic Change. (special issue on the Cultural Spaces of Climate)

Livingstone DN (2012) Reflections on the cultural spaces of climate. Climatic Change (special issue on the Cultural Spaces of Climate)

Lorenzoni I, Pigeon NF (2006) Public views on climate change: European and USA perspectives. Clim Chang 77:73-95

Naylor SK (2006) Nationalising provincial weather: meteorology in nineteenth-century Cornwall. Br J Hist Sci 39:1-27

Palutikof JP, Agnew MD, Hoard MR (2004) Public perceptions of unusually warm weather in the UK: impacts, responses and adaptations. Clim Res 26:43-59

Ross A (1991) Is global culture warming up? Social Text 28:3-30

Slocum R (2004) Consumer citizens and the cities for climate protection campaign. Environ Plann A 36:763782

Von Storch H, Stehr N (2006) Anthropogenic climate change: a reason for concern since the 18th century and earlier. Geogr Ann Series A Phys Geogr 88(2):107-113 